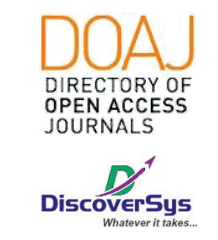

Published by DiscoverSys

\section{Utilisation of interactive media as health promotion in preventing and controlling blood sugar levels among type 2 diabetes mellitus patients: a systematic review}

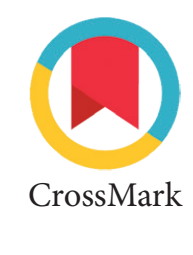

\author{
Ngurah Mahendra Dinatha ${ }^{1 *}$
}

\title{
ABSTRACT
}

Background: The use of interactive media as a health promotion media has continued to develop in the past few decades. This technology is used to manage various acute and chronic diseases, one of which is diabetes mellitus. This systematic review aims to describe an intervention that utilises technology as a tool in the form of interactive media in conducting preventative health promotion and glucose control for type 2 diabetes.

Methods: The databases used include ProQuest, PubMed, Science Direct and Google Scholar. The keywords used in article search are research, interactive media, type 2 diabetes, health promotion, telemedicine, web-based, obesity, diabetes exercise, walking, glucose control. Inclusion criteria are 1) articles published in 2014-2018 in English, 2) articles which the main content is about using interactive media for diabetes type 2 problems. Exclusion criteria are 1) literature that is not relevant to the purpose of writing, 2) researching the interactive media but not applied to the problem of type 2 diabetes, 3) duplication, and 4) published articles incomplete. Thus, there were 1442 articles and only 12 articles that were used in accordance with the inclusion and exclusion criteria.

Results: This systematic review found that the effective results in the implementation of preventive health promotion and glucose control of type 2 diabetes by utilising technology particularly interactive media. Conclusion: The 12 articles used in this study revealed that the implementation of preventive health promotion by utilising technology particularly interactive media was sufficient to control the glucose levels of among patients with type 2 Diabetes Mellitus.
${ }^{1}$ Public Health Postgraduate Program, Faculty of Medicine, Universitas Udayana, Bali, Indonesia
${ }^{*}$ Correspondence to: Ngurah Mahendra Dinatha; Public Health Postgraduate Program, Faculty of Medicine, Universitas Udayana, Bali, Indonesia; ngurahm87@gmail.com

\section{INTRODUCTION}

The prevalence of diabetes mellitus in Indonesia, according to WHO, has been increased significantly to 21.3 million in the coming 2030 . The increasing number of people with diabetes mellitus in Indonesia can also be seen from the comparison of Basic Health Research data (Riskesdas) in 2007 where $5.7 \%$ of patients to $6.9 \%$ of patients or around 9.1 million in $2013 .{ }^{1}$

Diabetes mellitus will have an impact on the quality of life of sufferers. Moreover, more serious problems will be faced if the sufferers have a sedentary lifestyle by consuming high fat and high-sugar foods, lack of physical activity, and unable to maintain an ideal body weight. ${ }^{2}$

The efforts to improve the quality of human life are to strengthen health, including promotion and preventive actions. One of the ways of health service provided by health workers is useful information, communication and education through health promotion by utilising technology as a tool in the form of interactive media on the management of diabetes mellitus so that it is not continued to complications. ${ }^{2,3}$ Health promotion is a process of communication and behaviour changes through health education. Health promotion is an important constituent of the public health system. The main goal is to empower individuals and communities for health purposes that results in healthy living behaviour. Health promotion activities can achieve maximum results if its methods and media are following the goals. ${ }^{4}$

The success of health promotion in the community depends on the method and media used. ${ }^{4}$ The more senses used to receive a message that is conveyed, the more knowledge gained. The use of tools or media in carrying out health promotion will significantly help to send messages to someone or society more clearly. ${ }^{4}$ In addition, interesting media will foster confidence, so that cognitive, affective and psychomotor abilities towards health problems can be maximised. The use of interactive media is one of the solutions that can be used for health promotion to prevent diabetes mellitus.

Services which are delivered in a comprehensive and quality manner to patients with diabetes mellitus using interactive media in the form of applications 
is a method to increase awareness of the patients with diabetes mellitus. It can change their diet and lifestyle to be healthier so that they can idealise their weight, waist circumference, blood pressure, and mostly control the blood glucose levels. ${ }^{5}$

Interactive media that contains applications are the most effective tools for health promotion in a community, but their application will not be effective if the features in the application are not updated according to the needs of the population in maintaining their behaviour change. A study reported that interactive media applications and messaging services are summarised in an app called "smartAPPetite" that focuses on the stages of behaviour changes that are validated in healthy dietary program. ${ }^{6}$

Based on the previous explanations, the researcher is interested in examining the use of interactive media as a means of health promotion toward preventing and controlling sugar levels of type 2 diabetes mellitus. The objective of this systematic review is to gain a deeper understanding of the use of interactive media for educational, promotional and as a preventive measure to prevent and control the sugar level of type 2 diabetes simultaneously. The results of the literature review can be used as a suggestion to health workers, especially nurses, government and non-governmental organisations in choosing health promotion media in people with type 2 diabetes mellitus.

\section{METHODS}

The data sources in this paper are Pro-Quest, PubMed, Science Direct and Google Scholar. Some

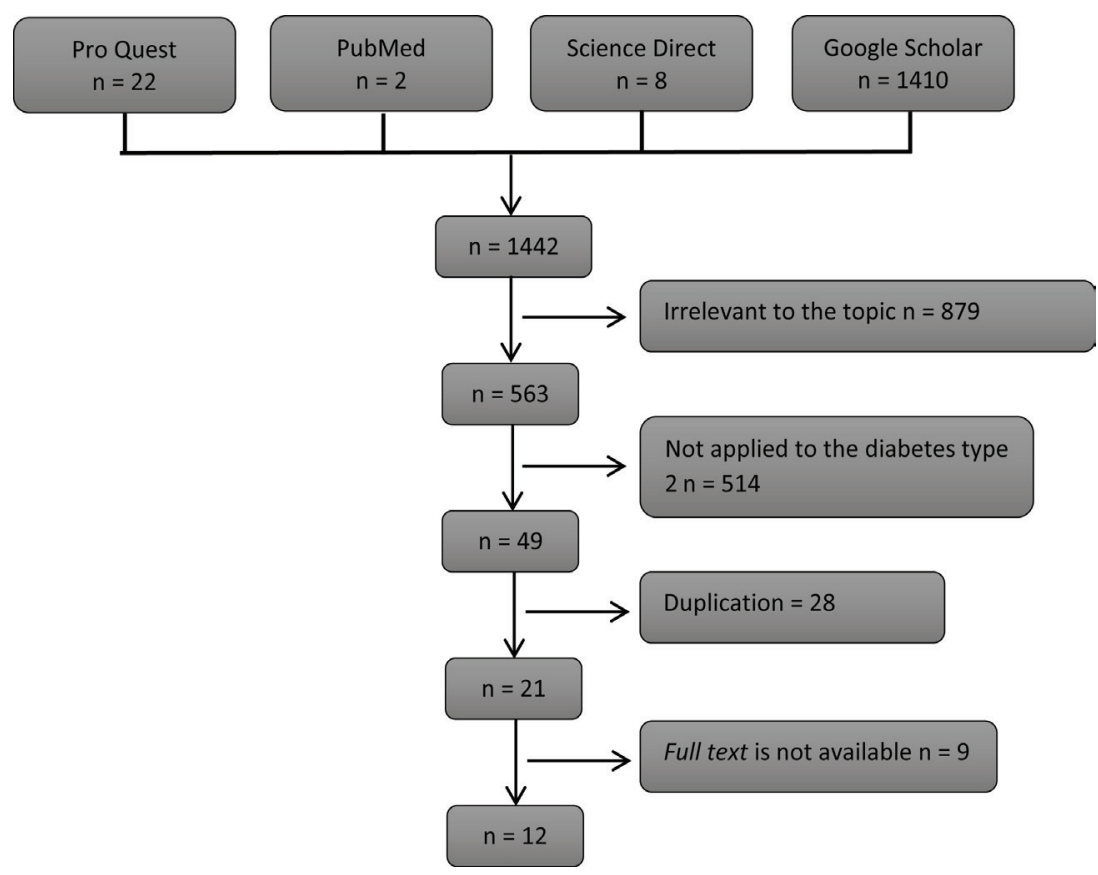

Figure 1 Systematic flow in the Strategy of Literature Searching keywords are also used such as research, interactive media, type 2 diabetes, health promotion, telemedicine, web-based, obesity, diabetes exercise, walking, glucose control. Some of the inclusion criteria are 1) articles published during 2014-2018 in English, 2) articles which the main content is about using interactive media for diabetes type 2 problems. Some of the exclusion criteria are 1) literature that is not relevant to the purpose of writing, 2) researching the interactive media but not applied to the type 2 diabetes problems, 3 ) duplication and 4) incomplete published articles. The systematic flow to search for articles in this paper is presented as follows below.

\section{RESULTS AND DISCUSSION}

The effective use of interactive media for type 2 diabetes mellitus should help glycemic control and improve clinical and metabolic outcomes. The recommendations that can be used are the health principle of eating for the family to promote healthy living habits throughout the period while maintaining social and psychological interactions. Valuable energy and nutrient intake must be aimed at maintaining ideal body weight, improving health and growth, optimising glycemic control while minimising the risk of chronic complications. ${ }^{7}$

The effectiveness of eHealth interventions on weight loss makes it a reference for further research that leads to diverse racial and ethnic populations with limited educational levels. ${ }^{8,9}$ Besides, future research should also focus on ways to optimise behavioural support.

While many applications for weight loss, there are only a few recent studies regarding their ability to facilitate adherence to weight loss programs. ${ }^{10}$ Several studies published in general show that the use of interactive media is associated with greater compliance and weight gain, and the results cannot be optimally performed. There are still components in interactive media that can control all these problems.

There is limited evidence to support the effectiveness of interactive media to improve glycemic control for adults with type 2 diabetes. The findings strongly suggest that efforts to increase user satisfaction are needed to incorporate the principles of existing health behaviour change and match applications to user characteristics because it will increase the therapeutic effect of the implementation of diabetes. ${ }^{11}$

Interactive media can be used to promote type 2 diabetes mellitus at various levels of society. Interactive media can also be used in small groups or large groups of people. ${ }^{12}$ Interactive media can reach many people, not just adolescence, but for 
Table 1 Literature Reviews collected during the literature search strategy was conducted on databases

\begin{tabular}{|c|c|c|c|c|c|c|c|}
\hline No & $\begin{array}{l}\text { Researchers } \\
\text { and Years }\end{array}$ & Research Title & $\begin{array}{l}\text { The setting } \\
\text { of the Study }\end{array}$ & Outcome & $\begin{array}{l}\text { Research } \\
\text { Method }\end{array}$ & Sample & Quality \\
\hline 1 & $\begin{array}{l}\text { Dwi et al. } \\
(2017)\end{array}$ & $\begin{array}{l}\text { Predictors of diabetes } \\
\text { self-management } \\
\text { among people with type } \\
2 \text { diabetes in Indonesia: } \\
\text { Application theory of }\end{array}$ & $\begin{array}{l}\text { Malang City, } \\
\text { East Java, } \\
\text { Indonesia }\end{array}$ & $\begin{array}{l}\text { Significant predictors of diabetes } \\
\text { self-management are treatment, self- } \\
\text { efficacy, and perceived situational } \\
\text { influences }\end{array}$ & $\begin{array}{c}\text { Cross } \\
\text { sectional }\end{array}$ & 127 & Moderate \\
\hline
\end{tabular}

$\begin{array}{cl}\text { Eastern } & \text { Improvement of self-efficacy is } \\ \text { North } & \text { associated with a decrease in anxiety } \\ \text { Carolina } & \text { about treatment }(\mathrm{r}=0.64)\end{array}$

based diabetes medication tool to improve adherence: A pilot study.

$3 \quad$ Lari et

al. (2017)

Effect of electronic education based on health promotion model on physical activity in diabetic patients.

4 Kamboj \& Krishna (2017)

5 Jacobs et al. (2017)

6

Pludwinski et al., (2017) al. (2015)
Pokémon GO: An innovative smartphone gaming application with health benefits

Adherence as a predictor of weight loss in a commonly used smartphone application

Participant experiences in a smartphone-based health coaching intervention for type 2 diabetes: A qualitative inquiry

Evaluating the epic electronic medical record system: A dichotomy in perspectives and Solution recommendations
Bushehr, a The comparison of two groups southwestern showed that there were no differences province in

Iran recorded in family support scores between the two groups $(\mathrm{p}=0.052)$, but health status, self-efficacy, benefits, and friend support were felt higher, and barriers were perceived to be lower in the multimedia group than the control group

San Pokémon GO exemplifies a very

Francisco, successful smartphone application

California that promotes health specifically by providing the most effective walking exercises.

North The use of smartphone applications is America, associated with significant short-term Africa, Asia, weight loss, and this weight loss is Australia,

Europe, New

Zealand,

Latin

America

Toronto,

Canada

The qualitative data analysis results in deriving four main themes that describe the participants' experience:

(a) smartphones and software, explaining the use of smartphone and its relation to health behaviour;

(b) The health trainers describe the relationship between the trainer and clients assisted by the use of smartphones; (c) the whole observation explains the overall intervention; and (d) frustration in managing the critical perspective of T2DM from the patient's perspective.

Amsterdam The themes identified in their survey include a lack of interaction with health care providers, difficulties in scheduling appointments, lack of timely communication with health care providers, and challenges in managing complex diabetes care
Descriptive $51 \quad$ Moderate

Quasi-

76

Moderate

Experimental

Descriptive

Low

Quasi-

7633

High

Experimental

Qualitative

11

Low

$$
\begin{aligned}
& \text { Survey } \\
& \text { And }
\end{aligned}
$$

31

Moderate

Intervention 
Table 1 Continued

\begin{tabular}{|c|c|c|c|c|c|c|c|}
\hline No & $\begin{array}{l}\text { Researchers } \\
\text { and Years }\end{array}$ & Research Title & $\begin{array}{l}\text { The setting } \\
\text { of the Study }\end{array}$ & Outcome & $\begin{array}{l}\text { Research } \\
\text { Method }\end{array}$ & Sample & Quality \\
\hline 8 & $\begin{array}{l}\text { Wilczynska } \\
\text { et al. (2016) }\end{array}$ & $\begin{array}{l}\text { Rationale and study } \\
\text { protocol for the 'eCoFit' } \\
\text { randomised controlled } \\
\text { trial: Integrating } \\
\text { smartphone } \\
\text { technology, social } \\
\text { support and the outdoor } \\
\text { physical environment to } \\
\text { improve health-related } \\
\text { fitness among adults at } \\
\text { risk of, or diagnosed with, } \\
\text { Type } 2 \text { Diabetes }\end{array}$ & Australia & $\begin{array}{l}\text { eCoFit is an innovative multi- } \\
\text { component intervention, which } \\
\text { integrates smartphone technology, } \\
\text { supports social and outdoor physical } \\
\text { environments to promote aerobic } \\
\text { training and PA resistance among } \\
\text { at-risk adults, or is diagnosed with } \\
\text { T2D. The findings will be used to } \\
\text { guide future interventions and to } \\
\text { develop and implement effective } \\
\text { community-based prevention } \\
\text { programs. }\end{array}$ & $\begin{array}{c}\text { Quasi- } \\
\text { Experimental }\end{array}$ & 84 & Moderate \\
\hline 9 & $\begin{array}{l}\text { Al-Ozairi et } \\
\text { al. }(2018)\end{array}$ & $\begin{array}{l}\text { Diabetes and } \\
\text { TelecommunicationS } \\
\text { (DATES) } \\
\text { study to support self- } \\
\text { management for } \\
\text { people with type } \\
2 \text { diabetes: a randomised } \\
\text { controlled trial }\end{array}$ & Kuwait & $\begin{array}{l}\text { Cellphones have outstanding } \\
\text { potential for the prevalence of } \\
\text { diabetes; visual messages delivered } \\
\text { can provide psychological support } \\
\text { and also motivate someone to have } \\
\text { a healthy lifestyle as well as to avoid } \\
\text { diabetes. }\end{array}$ & $\begin{array}{c}\text { Quasi- } \\
\text { Experimental }\end{array}$ & 572 & High \\
\hline 11 & $\begin{array}{l}\text { Quinn et al. } \\
(2014)\end{array}$ & $\begin{array}{l}\text { Mobile Diabetes } \\
\text { Intervention for } \\
\text { Glycemic Control in } 45 \text { - } \\
\text { to } 64 \text {-Year-Old Persons } \\
\text { With Type } 2 \text { Diabetes }\end{array}$ & $\begin{array}{l}\text { Baltimore, } \\
\text { Maryland }\end{array}$ & $\begin{array}{l}\text { Interventional patients receive } \\
\text { telephone and individual web portals } \\
\text { training. Control patients received } \\
\text { regular care. Patients are grouped } \\
\text { into two age groups: younger } \\
\text { ( }<55 \text { years) and older ( } \geq 55 \text { years) } \\
\text { groups. Interventions resulted in } \\
\text { a greater } 12 \text {-month decrease in } \\
\text { HbA1c, compared to regular care, } \\
\text { for patients in both age groups } \\
\text { (p }<.0001) \text {. Among older patients, } \\
\text { HbA1c changed by }-1.8 \%(\text { trusting } \\
95 \% \text { interval [CI] = }[.42 .4,-1.1]) \text { in } \\
\text { the intervention group and }-0.3 \% \\
(95 \% \text { CI }=[-0.9,+0.3]) \text { in the control } \\
\text { group. Among younger patients, } \\
\text { HbA1c changed by } .02 .0 \%(95 \% \mathrm{CI}= \\
[-2.5,-1.5]) \text { in the intervention group } \\
\text { and }-1.0 \%(95 \% \mathrm{CI}=[-1.6,-0.4]) \text { in } \\
\text { the control group. }\end{array}$ & $\begin{array}{c}\text { Quasi- } \\
\text { Experimental }\end{array}$ & 118 & Moderate \\
\hline 12 & $\begin{array}{l}\text { Sukumar et } \\
\text { al. (2018) }\end{array}$ & $\begin{array}{l}\text { Baby Steps - a structured } \\
\text { group education } \\
\text { programme with } \\
\text { accompanying mobile } \\
\text { web application designed } \\
\text { to promote physical } \\
\text { activity in women with } \\
\text { a history of gestational } \\
\text { diabetes: study protocol } \\
\text { for a randomised } \\
\text { controlled trial }\end{array}$ & UK & $\begin{array}{l}\text { The Baby Steps program can be } \\
\text { applied as a primary care-based } \\
\text { intervention for women with GDM } \\
\text { referred to the postnatal period. } \\
\text { This can help them to make lifestyle } \\
\text { changes that can reduce the risk of } \\
\text { T2D in the future. }\end{array}$ & $\begin{array}{c}\text { Quasi- } \\
\text { Experimental }\end{array}$ & 290 & High \\
\hline
\end{tabular}

all groups. Furthermore, interactive media can also be used on bodies or organisations related to health. However, sometimes the use of interactive media does not have a significant impact on specific areas. This occurs because of the inappropriate interventions used in the interactive media used in the area, such as language and culture inappropriateness. ${ }^{8}$ 
Interactive media is beneficial to convey information to someone or a broader community. Through media, material that is informed will be delivered faster and can be easily understood. Accurately, information related to diabetes problems will be conveyed easily, both as a means of promotion and health education. ${ }^{13}$ One of how health promotion is achieved is by disseminating relevant health information to specific individuals and communities. ${ }^{14}$ This means that the interactive media used must be in accordance with the needs of the community in a particular area.

The ease of information on diabetes delivered through interactive media is influenced by several factors such as simple design, easy operating navigation, cultural elements that are appropriately applied to target areas, feedback, interactive planners, and quizzes provide new experiences for the community. ${ }^{15}$ A simple design of multimedia interventions, clear visual information, person-centred adjustments, clear goals, feedback, cultural specificity and exploration of excellent interactive features will make it easier for someone to understand the conveyed information about diabetes problems. This certainly will improve one's understanding of the health material provided. Interactive media is a new and attractive health promotion media while providing unique experiences to the community. ${ }^{16}$ The existence of new and interesting things, then the interest and motivation of the community to get in touch, know and apply healthy living habits will increase. For those who are in low health literacy groups, the planning and development of interventions carried out on interactive media must be adjusted to the age, gender and culture that can be accepted by the group. ${ }^{16}$

The use of interactive media to deliver information about diabetes problems is very useful to use. Moreover, the use of this media focuses on the knowledge, attitudes and behaviours of a person or society towards the diabetes problems that are faced. ${ }^{17}$ The function of the use of interactive media is first as a means of promotion or media for providing information to the community that is effective, easy to understand and on target. This is supported by components from interactive media that display writings, images, sounds and videos that will undoubtedly provide an accurate picture of the health problems. The community will understand more, and it is easy to imagine what might happen if diabetes in the community is not addressed quickly and precisely. Information relating to health problems will also be easily conveyed, both as a means of health promotion, health education or other health problems. ${ }^{12}$

In addition to health promotion media, interactive media is also used to increase the knowledge, attitudes and behaviour of a person or group of people towards the prevention of diabetes. For example, eCoFit is an innovative multi-component intervention, which integrates smartphone technology, social support and outdoor physical environments to promote aerobic training and PA resistance among at-risk adults, or diagnosed with T2D. The findings will be used to guide future interventions and to develop and implement effective community-based prevention programs. ${ }^{11}$ Cellular and interactive media technology increase the knowledge of health, health promotion, and prevention of diseases. Interactive media can also be used in the form of alternative reality games to reduce diabetes problems. Pokémon GO exemplifies a very successful smartphone application that promotes health specifically by providing the most effective walking exercises. ${ }^{10}$

The use of interactive media must get special assistance to make the participants receive positive feedback from information on diabetes given. ${ }^{12}$ The use of interactive media means that there is an interaction between the user and the interactive media that is used; this process is where the assistance must occur to make sure that information obtained is optimised. In addition to benefiting the community, with the presence of interactive media, health practitioners will find it easier to deliver health material. It aims to be able to direct people's thoughts and behaviour in a better direction.

The use of interactive media has been proven to increase people's knowledge, attitudes and behaviour towards the health problems they face. This also has an impact on how the community takes preventive action on diabetes problems that arise in an area. ${ }^{12}$

Interactive media can increase knowledge, attitudes and behaviour of a person or society towards the prevention of diabetes in a particular area. Judging from the improvement of the knowledge, people will surely understand more about the mechanism, how to deal with it and also how to do the initial treatment. Furthermore, in the sense of the people who already have good knowledges, they will certainly be more vigilant and maintain their health to avoid the emergence of illness. The quality of life of the community will also increase nonetheless. Lastly, the most important thing is how interactive media shape the behaviour of the community always to live healthy so that it has an impact on a much better quality of life.

\section{CONCLUSION}

The use of interactive media functions as a tool to improve health condition through applications that contain health information related to diabetes mellitus, diabetes prevention education videos, therapy videos for glucose control modalities, Pokémon go games to increase physical activity, 
healthy diet guidelines for weight control in accordance with BMI, a history profile menu for people with diabetes mellitus. However, several obstacles arise, namely supervision and mentoring that are still less effective, as well as cultural and language constraints on interactive media that do not suit each of the different regions.

In the implementation of interactive media, the strategy of delivery, assistance and supervision must be done well. This aims to make the community understand and obey the program provided. The content and material provided are expected to use language that is easy to understand and in accordance with the culture of the local community.

\section{CONFLICT OF INTEREST}

There is no competing interest regarding the manuscript

\section{FUNDING}

None

\section{AUTHOR CONTRIBUTION}

The author is responsible for the article from the conceptual framework until reporting the results.

\section{REFERENCE}

1. Riset Kesehatan Dasar RI. Proporsi Penderita Diabetes Melitus di Indonesia. Pusat Data dan Informasi. 2007:1-8

2. Sørensen M, Korsmo-Haugen HK, Maggini M, Kuske S, Icks $\mathrm{A}$, Rothe $\mathrm{U}$, et al. Health promotion interventions in type 2 diabetes. Ann Ist Super Sanita. 2015;51(3):192-8

3. Al-Khalifa A, Mathew TC, Al-Zaid NS, Mathew E, DashtiHM. Therapeutic role of low-carbohydrateketogenic diet in diabetes. Nutrition. 2009; 25(11-12):1177-1185.

4. Wakefield MA, Loken B, Hornik RC. Use of mass media campaigns to change health behaviour. Lancet. 2010;376(9748):1261-71.

5. Inggar Octa Pusthika. Pengaruh Frekuensi Konseling Gizi dan Gaya Hidup terhadap Indeks Massa Tubuh, Lingkar Pinggang, Tekanan Darah, dan Glukosa Darah pada Penderita Diabetes Mellitus. [Skripsi] Fakultas Kedokteran Universitas Diponegoro. 2011; 1-22.
6. Gilliland J, Sadler R, Clark A, O'Connor C, Milczarek M, Doherty S. Using a Smartphone Application to Promote Healthy Dietary Behaviours and Local Food Consumption. Biomed Res Int. 2015;2015:841368.

7. Dwi A, Amatayakul A, Karuncharernpanit S. Predictors of diabetes self-management among type 2 diabetics in Indonesia: Application theory of the health promotion model. Int J Nurs Sci. 2017;4(3):260-265

8. Lari H, Tahmasebi R, Noroozi A. Effect of electronic education based on health promotion model on physical activity in diabetic patients. Diabetes Metab Syndr. 2018;12(1):45-50.

9. Chai S, Yao B, Xu L, Wang D, Sun J, Yuan N, et al. The effect of diabetes self-management education on psychological status and blood glucose in newly diagnosed patients with diabetes type 2. Patient Educ Couns. 2018;101(8):1427-1432.

10. Kamboj AK, Krishna SG. Pokémon GO : An innovative smartphone gaming application with health benefits. Prim Care Diabetes. 2017;11(4):397-399

11 Jacobs S, Radnitz C, Hildebrandt T. Adherence as a predictor of weight loss in a commonly used smartphone application. Obes Res Clin Pract. 2017;11(2):206-214.

12. Pludwinski S, Ahmad F WN, Wayne N, Ritvo P. Participant experiences in a smartphone based health coaching intervention for type 2 diabetes: A qualitative inquiry. J Telemed Telecare. 2016;22(3):172-8.

13. Davis Z, Khansa L. Evaluating the epic electronic medical record system : A dichotomy in perspectives and solution recommendations. Heal Policy Technol. 2016;5(1):65-73.

14. Wilczynska M, Lubans DR, Cohen KE, et al. Rationale and study protocol for the 'eCoFit' randomized controlled trial: Integrating smartphone technology, social support and the outdoor physical environment to improve health-related fitness among adults at risk of, or diagnosed with, Type 2 Diabetes. Contemp Clin Trials. 2016;49:116-25.

15. Al-ozairi E, Ridge K, Taghadom E, de Zoysa N, Tucker C, Stewart $\mathrm{K}$ et al. Diabetes and TelecommunicationS (DATES) study to support self-management for people with type 2 diabetes: a randomized controlled trial. BMC Public Health. 2018;18(1):1249.

16. Quinn CC, Shardell MD, Terrin ML, Barr EA, Park D, Shaikh F, et al. Mobile Diabetes Intervention for Glycemic Control in 45- to 64-Year-Old Persons With Type 2 Diabetes. J Appl Gerontol. 2016;35(2):227-43.

17. Sukumar N, Dallosso H, Saravanan P, Yates T, Telling C, Shorthose K, et al. Baby Steps - a structured group education programme with accompanying mobile web application designed to promote physical activity in women with a history of gestational diabetes : study protocol for a randomised controlled trial. Trials. 2018;19(1):682.

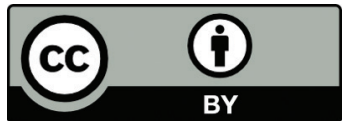

This work is licensed under a Creative Commons Attribution 